Article

\title{
Forest Inventory with Terrestrial LiDAR: A Comparison of Static and Hand-Held Mobile Laser Scanning
}

\author{
Sébastien Bauwens ${ }^{1, t, *}$, Harm Bartholomeus ${ }^{2, t, *}$, Kim Calders $^{3,4}$ and Philippe Lejeune ${ }^{5}$ \\ 1 TERRA Research Unit, Gembloux Agro-Bio Tech, University of Liège, Passage des Déportés 2, \\ Gembloux 5030, Belgium \\ 2 Laboratory of Geo-information Science and Remote Sensing, Wageningen University, Droevendaalsesteeg 3, \\ Wageningen 6708 PB, The Netherlands \\ 3 Earth Observations, Climate and Optical Group, National Physical Laboratory, Hampton Road, Teddington, \\ Middlesex TW11 0LW, UK; kim.calders@npl.co.uk \\ 4 Department of Geography, University College London, Gower Street, London WC1E 6BT, UK \\ 5 BIOSE Research Unit, Gembloux Agro-Bio Tech, University of Liège, Passage des Déportés 2, \\ Gembloux 5030, Belgium; p.lejeune@ulg.ac.be \\ * Correspondence: sebastien.bauwens@ulg.ac.be (S.B.); harm.bartholomeus@wur.nl (H.B.); \\ Tel.: + 32-81-62-26-42 (S.B.); +31-317-48-17-92 (H.B.) \\ + These authors contributed equally to this work.
}

Academic Editors: Juha Hyyppä, Xinlian Liang and Eetu Puttonen

Received: 16 April 2016; Accepted: 6 June 2016; Published: 21 June 2016

\begin{abstract}
The application of static terrestrial laser scanning (TLS) in forest inventories is becoming more effective. Nevertheless, the occlusion effect is still limiting the processing efficiency to extract forest attributes. The use of a mobile laser scanner (MLS) would reduce this occlusion. In this study, we assessed and compared a hand-held mobile laser scanner (HMLS) with two TLS approaches (single scan: SS, and multi scan: MS) for the estimation of several forest parameters in a wide range of forest types and structures. We found that SS is competitive to extract the ground surface of forest plots, while MS gives the best result to describe the upper part of the canopy. The whole cross-section at $1.3 \mathrm{~m}$ height is scanned for $91 \%$ of the trees (DBH $>10 \mathrm{~cm}$ ) with the HMLS leading to the best results for DBH estimates (bias of $-0.08 \mathrm{~cm}$ and RMSE of $1.11 \mathrm{~cm}$ ), compared to no fully-scanned trees for SS and $42 \%$ fully-scanned trees for MS. Irregularities, such as bark roughness and non-circular cross-section may explain the negative bias encountered for all of the scanning approaches. The success of using MLS in forests will allow for 3D structure acquisition on a larger scale and in a time-efficient manner.
\end{abstract}

Keywords: forestry; terrestrial laser scanning; hand-held mobile laser scanning; HMLS; TLS; SLAM; digital elevation model; stem mapping

\section{Introduction}

Forests provide various ecosystem services, such as carbon storage, maintaining biodiversity, and wood production. Information on the current state and recent changes of forests are important basics for forest managers, policy-makers, conservation planners, and forest scientists. Forest inventories are the main tool used to describe the structure and quantify the forest resources. For large areas, the traditional approach is a statistical inventory of the forest, which results in the establishment of sample plots. Forest information deduced from parameters collected in the plots is then summarized for each stratum of the area inventoried. 
Field parameters in sample plots are traditionally limited to the measurement methods available or the efficiency and the accuracy with which the measurement can be taken [1]. The tree parameters most frequently measured and used are diameter at breast height $(\mathrm{DBH})$ of all trees and a sample of heights as they are strongly related to stem volume and above-ground biomass of the tree. Other tree attributes, such as the location, tree height, and height of the first living branch may also be recorded but are often not measured for every tree on sample plots because these measurements are labor-intensive [2]. An automated, instrument-based technique having the potential to augment conventional manual techniques would be of great interest, particularly in terms of objectivity and repeatability of results and time saving [3].

In remote sensing, the emergence of Light Detection and Ranging (LiDAR) in the late 1990s provided new insights to assess forest structure and the three-dimensional distribution of plant canopies at the plot level and regional scales. LiDAR is an active remote sensing method that can accurately measure distances by transmitting laser energy and analyzing the returned energy. LiDAR can be operated from spaceborne, airborne, or terrestrial platforms, with each platform serving specific forest inventory needs. Static terrestrial laser scanning (TLS), also known as ground-based LiDAR, offers the capacity to retrieve the 3D vegetation structure with millimeter accuracy [4].

The interest on TLS as a tool for forest plot measurement started in the past decade. The first reports based on this technique were published in 2003 [5-7] and 2004 [8-11]. The objective of these early studies was to explore the TLS potential for basic field measurements, such as measuring DBH and tree height [2]. Other variables of tree structure (e.g., crown, stem, or whole tree dimensions) can be observed and measured in the TLS data by time-consuming manual interpretation $[10,12,13]$, although semiautomatic algorithms have been developed with various degrees of success [14-19]. Recently, a promising fully-automatic processing for volume estimates at the plot level has been proposed by Raumonen [20]. Data describing specific characteristics of individual trees can also be summarized to describe characteristics at the plot level, as stem density [10], the overall volume of biomass [18-21], or the fuel capacity in a forest [22]. Stand parameters can also be directly computed from TLS data as basal area [23], gap fraction [24,25], and Leaf Area Index (LAI ) [26]. In addition to algorithms improvements for extracting forest attributes of TLS data, the acquisition protocol should also be optimized in the plot.

The occlusion effect occurring in TLS data is one of the main limitations of the use of this tool in forestry. Occlusion is the fact that some stems, branches, twigs, and leaves, or parts of it, may not be scanned as they are hidden by elements closer to the scanner. This is inherent to the static nature of TLS. To tackle the occlusion effect, the plot can be scanned with multiple scans (MS) instead of one single scan (SS) in the center of the plot or a statistical methods can be used [23-27]. The former solution, the MS approach, requires pre-scan preparations (setting up the plot and target placement). The targets are then used as tie-points between the single scan data during the co-registration process. The pre-scan preparations in the field for the multi-scan approach reduce the cost-effectiveness of this technology, whereas the statistical approach is limited to a few stand parameters, such as basal area estimations.

Laser scanners have recently been placed on moving ground platforms and designated as mobile laser scanners (MLS). MLS systems typically combine a laser scanner with an inertial measurement unit (IMU) and Global Navigation Satellite System (GNSS), making it analogous to airborne laser scanning (ALS). The quality of the final data (registered point cloud) is then related to the precision and accuracy of the three components, as well as the synchronization of these components. The accuracy of the MLS data are usually inferior to registered multi-scan TLS data [28]. For instance, MLS mounted on a car was reported to have an elevation accuracy of around $3.5 \mathrm{~cm}$ and a planimetric accuracy of $2.5 \mathrm{~cm}$ [29]. The advantage of MLS is the reduction of the occlusion effects, as well as increasing the areas scanned. The introduction of MLS in tree measurement started in early 2010 [30,31]. These first studies focused on sparse urban trees scanned from a MLS mounted on car. To our knowledge, no MLS study were conducted in forest environment before 2013 [32]. The limitation of the use of MLS in 
forest areas is probably due to the low GNSS signal detection under forest cover leading to too low accuracy. Moreover, the use of a moving platform limits the use in forest ecosystems, since mounting the devices on a car, quad, or all-terrain vehicle may still not allow spatially-continuous mapping, nor does it correspond well with the non-destructive nature of LiDAR data acquisition. To encompass the moving limitation of MLS, the Finnish Geodetic Institute created a backpack mounted laser scanner [33] leading to the concept of personal laser scanning (PLS). An updated version of their PLS was tested in a forest environment, but the lack of proper satellite visibility during the field measurements led to less accurate platform positions, which also undermined the heading angle estimates [28].

Recently, a hand-held mobile laser scanning (HMLS) system was introduced by Bosse et al. [34], using the movement of the operator as a platform. This system (further described in the materials section) tackles some drawbacks of the traditional TLS setup, since the movement through the plot results in a theoretically unlimited number of scan-positions, which minimizes occlusion effects. Unlike MLS, forest cover is no longer a limitation, as HMLS does not need satellite positioning (GNSS). To assure good portability of the instruments concessions are made on the quality of the LiDAR module, resulting in a limited range $(20-30 \mathrm{~m})$ and lower accuracy $(3 \mathrm{~cm})$. A first study was carried out by Ryding et al. [35] to study the potential of HMLS for forest surveys. Their study, which is conducted in a restricted forest area dominated by hash and with small trees (DBH mean $<10 \mathrm{~cm}$ ), showed first promising results in using this technology.

In this study, our main objective was to assess and compare the HMLS and TLS approaches for the estimation of several forest parameters in a wide range of forest types and structures. The influence of topography and forest structure was also analyzed. The same LiDAR scanning protocols were applied in all the plots, one protocol for the HMLS and two protocols for the TLS (the single or the multi-scan approach).

\section{Materials and Methods}

\subsection{Instrumentation}

For the static TLS data acquisition a FARO Focus 3D 120 (FARO, 250 Technology Park Lake Mary, FL 32746, United States) is used. This scanner uses phase-shift-based LIDAR technology to measure the XYZ locations of objects and further returns the intensity of the returned LIDAR beam (905 $\mathrm{nm}$ wavelength and a beam divergence of $0.19 \mathrm{mrad}$ ). The FARO scanner has a maximum range of $120 \mathrm{~m}$ and can collect $9.76 \times 10^{5}$ points per second with an accuracy of $2 \mathrm{~mm}$ at $10 \mathrm{~m}$. Its lightweight $(5.2 \mathrm{~kg})$ construction, small size $(24 \mathrm{~cm} \times 20 \mathrm{~cm} \times 10 \mathrm{~cm})$ and short scanning time (e.g., 3 min without photograph with $1 / 5$ th of the full resolution) make it very appropriate for forest studies. The mixed pixels and range/intensity cross-talk effects, which limit the accuracy of phased-shifted based LiDAR at the edge of objects, were limited by enabling the "Clear Sky" and "Clear Contour" FARO filters in the hardware, as well as using the "ghost points" filter in the FARO Scene software. For each plot several FARO scans are done (see description further on), which are co-registered using 12 white spheres with a diameter of $19.5 \mathrm{~cm}$ that are placed within the plot.

As HMLS, we used the ZEB1, which consists of a 2D laser scanner (905 nm wavelength and a beam divergence of approximately $7 \mathrm{mrad}$ ), combined with an inertial measurement unit (IMU). These are both mounted on top of a spring, itself mounted on a hand grip [34]. The laser specifications cite a $30 \mathrm{~m}$ measurement range, but this is unlikely to be achieved outdoors (due to ambient solar radiation), and a survey swath of up to 15-20 m around the instrument is more realistic [36]. The hand-held part of the scanner $(0.7 \mathrm{~kg})$ is linked to a data logger carried in a backpack $(3.6 \mathrm{~kg})$. As the user carries the ZEB1 and walks through the environment, the scanner head swings back and forth creating a 3D scanning field with data being captured at the speed of movement. The scanner is a time-of-flight laser with a rate of 43,200 points/s ( 40 lines / s with a laser pulse interval of $0.25^{\circ}$ ) and a field of view of $270^{\circ}$ horizontally and approximately $120^{\circ}$ vertically. No additional information about the intensity of the returned signal is collected. 
ZEB1 uses the Simultaneous Localization and Mapping (SLAM) algorithm to locate the scanner in an unknown environment and to register the whole 3D point clouds, relying on both the IMU data and feature detection algorithms. Optimal functioning of the alignment algorithm occurs in environments with well-distributed static unique surface features all around the sensor, providing consistent laser returns to facilitate convergence in the processing algorithms [36].

Processing of the raw ZEB1 data to a consistent 3D point cloud has to be done through an online processing service offered by GeoSLAM, for which processing charges need to be paid. The total processing cost depends on the length of the walked track. Following the manufacturer, the final 3D point cloud product has a scan range noise (accuracy) at $10 \mathrm{~m}$ of $30 \mathrm{~mm}$ in an indoor environment and $50 \mathrm{~mm}$ in bright light environments.

\subsection{Study Area}

The study area is located in the south of Belgium, close to the town of Vencimont, which is part of the Ardenne natural region. In the surroundings a large variety of forest types occur, ranging from young production forests to old growth forest. The area has an average elevation of approximately 200 meters and is characterized by gentle hills, with elevation differences of approximately 100 meters. The climate is temperate maritime, with cool summers and moderate winters, and precipitation in all seasons (Köppen: $\mathrm{Cfb}$ ). Ten plots were laid out during the leaf-on period in varying forest types, forest structure, and covering different slope classes (Figure 1, Table 1 and Figure S1). The plots were selected in such a way that the maximum variation in forest types (broadleaved, coniferous, and mixed), tree density (NHA from 113 to 1344 trees/ha), and terrain properties (flat to steep) was achieved.

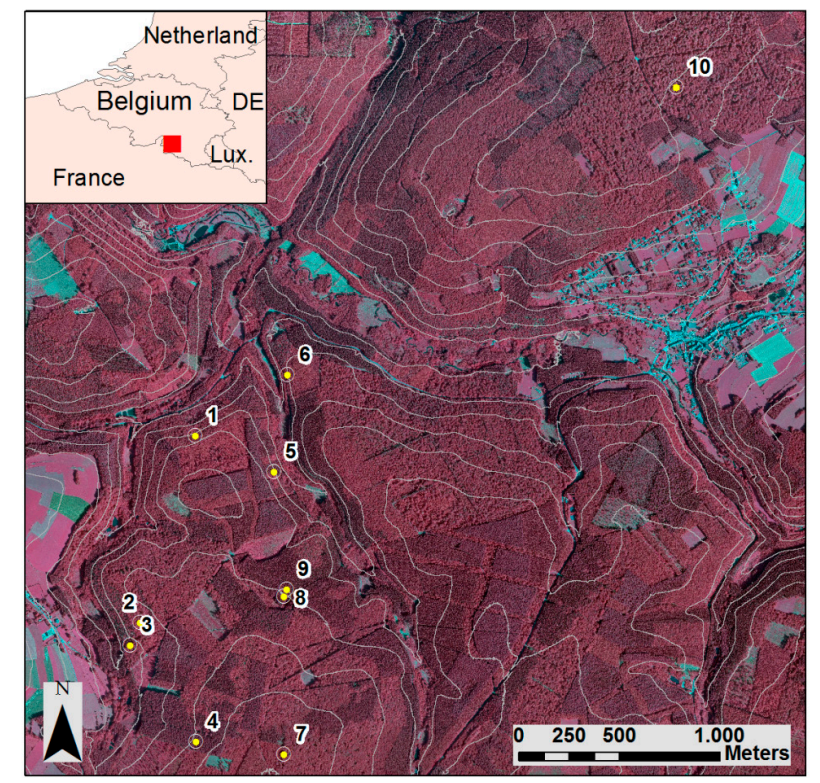

Figure 1. Overview of the study area, with the locations of the plots (IR orthoimage with contour interval of $20 \mathrm{~m}$ of elevation). 
Table 1. Plot description based on field inventory data.

\begin{tabular}{|c|c|c|c|c|c|c|c|c|}
\hline Plot & $\begin{array}{l}\text { Forest } \\
\text { Type }\end{array}$ & $\begin{array}{c}\text { Slope } \\
(\%)\end{array}$ & $\begin{array}{c}\text { Stand } \\
\text { Structure }\end{array}$ & Main Species & Under-story & $\begin{array}{c}\operatorname{NHA}(N) \\
\left(\text { trees ha }^{-1}\right)\end{array}$ & $\begin{array}{c}\text { GHA } \\
\left(\mathrm{m}^{2} \cdot \mathrm{ha}^{-1}\right)\end{array}$ & $\begin{array}{c}\mathrm{D}_{\min }-\mathrm{D}_{\max } \\
(\mathrm{cm})\end{array}$ \\
\hline 1 & B & 32.5 & Coppice & $\begin{array}{l}\text { Carpinus betulus } \\
\text { and Betula spp. }\end{array}$ & 1 & 835 (59) & 46.2 & 10-135 \\
\hline 2 & B & 11 & Even-aged & Fagus sylvatica & 0 & $113(8)$ & 29.8 & $44-68$ \\
\hline 3 & B & 11.2 & Uneven-aged & Fagus sylvatica & 1 & $127(9)$ & 28.6 & $14-80$ \\
\hline 5 & $\mathrm{C}$ & 28.7 & Even-aged & Picea abies & 0 & 410 (29) & 26.3 & $23-36$ \\
\hline 6 & M & 24.9 & Even-aged & $\begin{array}{l}\text { Quercus spp. and } \\
\text { Pinus sylvestris }\end{array}$ & 2 & 439 (31) & 20.0 & $11-40$ \\
\hline 7 & B & 5.1 & Uneven-aged & Fagus sylvatica & 1 & $283(20)$ & 33.5 & $10-82$ \\
\hline
\end{tabular}

Forest type, B: broadleaves, C: Coniferous, M: mixed. Understory, 0: no understory, 1: light understory, 2: dense understory; NHA is the number of trees $(\mathrm{DBH}>10 \mathrm{~cm})$ per hectare and $N$ is the number of trees in the plot. GHA is the basal area per hectare. $D_{\min }-D_{\max }$ shows the diameter of the thickest and smallest tree in the plot with a minimum DBH threshold of $10 \mathrm{~cm}$.

\subsection{Data Collection}

According to the results of Trochta et al. [37] in mixed natural forests dominated by beech, with MS (using two to four scan positions) $90 \%$ of the trees are detected (i.e., $50 \%$ of the cross-section at $1.3 \mathrm{~m}$ of height is visible) at a distance of $10-15 \mathrm{~m}$ of the scanners. This rate decrease to $80 \%$ when the SS setup is used. National forest inventory concentric plots have a maximum radius of less than $20 \mathrm{~m}$ and usually around $15 \mathrm{~m}$ for diameter at breast height (DBH) measurements. Following this information, and according to the objectives of the study, the plots were laid out with a radius of $15 \mathrm{~m}$. From the center points, poles were placed in the cardinal directions to indicate the locations for the FARO scanner. The directions were measured using a compass and the distance to the center of the plot is determined with the ultrasound instrument VERTEX IV. Locations in between the cardinal points were indicated with secondary poles, to simplify the ZEB1 data acquisition.

The TLS scanner was placed at the center of each plot and at the four cardinal points (Figure 2). If the cardinal point was too close to a tree included in the plot (distance less than 1 meter for instance) or just behind a tree, the scanner was slightly moved to a position where occlusion was less an issue. Full hemispherical scans with a point spacing of 0.045 degrees were done ( $1 / 5$ th of the full resolution) for a total of 28.4 million points per scan. Twelve spheres were set up within the plot as targets for co-registering the five scans.

A fixed pattern was followed for the HMLS data acquisition, which is shown in Figure 2. Scanning started in the south location. The scanning path is designed to have (1) a good distribution of the scanning positions (the plot is crossed four times and the path assures that the plot border is scanned at least once); (2) a pattern which reduces scanner range noise; and (3) avoids problems associated with drift, which can occur if the SLAM algorithm does not result in a good alignment. To prevent this, the path ends at the starting point (closing the loop), crosses the path several times (local loops) and some border sections are covered twice. For both scanning methods the time of data acquisition is recorded.

The reference field measurement was conducted at the same moment as the LiDAR scanning. The data collected were species, DBH, and tree position (azimuth and distance from the plot center) of all the trees with a diameter $>10 \mathrm{~cm}$ which are inside the $15 \mathrm{~m}$ radius plot. 

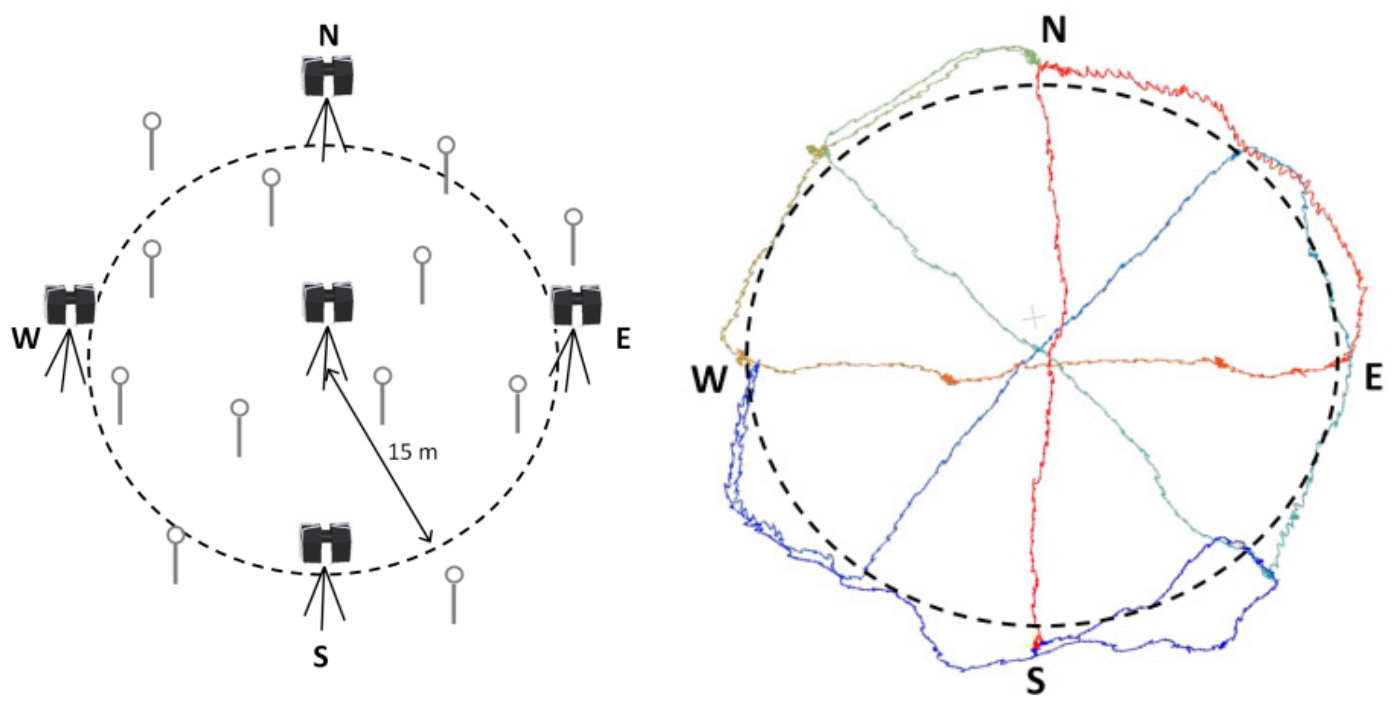

Figure 2. Locations of the TLS and the spheres (left) and walking pattern for the HMLS data acquisitions (starting in red and ending in dark blue) (right).

\subsection{LiDAR Data Pre-Processing}

The raw LiDAR data from the two scanners are processed to three point cloud datasets, which are used for further analysis and the extraction of forest parameters. The first dataset consists of the single TLS scan at the central position only. This implies that trees are, per definition, only observed from one direction and that occlusion will have a large influence on the derived forest parameters. This SS dataset will further be referred to as "FARO1". For the second dataset, the five TLS scans are co-registered using the white spheres within the Scene software [38]. This dataset will further be referred to as "FARO5". Resulting point clouds are used as the basis for the alignment of the FARO and ZEB1 data. ZEB1 raw data were uploaded to the GeoSLAM server, where the processing to a registered point cloud is done.

In order to ease the comparison of the registered point clouds and allow analysis at tree level, the ZEB1 point cloud is rotated and translated to the FARO5 data. First, a rough alignment was done by selecting corresponding points and using the align function in CloudCompare [39]. If no corresponding point were found, the ZEB1 was manually moved and rotated to match the FARO point cloud. These steps resulted in a rough alignment with an accuracy of approximately 5-20 cm. To improve the alignment, the Hybrid Multi-Station Adjustment (HMSA) in RiScan Pro 2.0 [40], was used. The HMSA algorithm modifies the orientation and position of each dataset in several iterations to calculate the best overall fit, for which point cloud features like planes and meshes are used. First, digital terrain models (DTMs) with different resolutions (FARO5: $50 \mathrm{~cm}$; ZEB1: $50 \mathrm{~cm}$ and $10 \mathrm{~cm}$ ) are computed. The FARO and ZEB1 DTMs are then aligned automatically in the HMSA process, thus aligning the point clouds as well. The final alignment was visually checked by making cross-sections of the point cloud data. For satisfactory results multiple (3 to 7) subsequent MSA runs were needed. This procedure is not required if the ZEB1 is used in an operational setting, as long as data only have to be collected at the plot level. Since the ZEB1 is not equipped with an internal GPS system, geo-rectification of the data would require additional processing steps, like placing artificial targets of which the location is known.

\subsection{Scanning Completeness of the Trees}

First, the completeness of the stem point cloud is compared between the three scanning methods: FARO1, FARO5, and ZEB1. The analysis is carried out on the top plan view with a sliced point cloud at a height of $125-135 \mathrm{~cm}$ above the terrain. Thus, cross-sections of the stems appear as a partial or full ring. Depending on the degree of ring closure, cross sections are classified into five quality 
classes: (1) <25\%; (2) 25\%-50\%; (3) 50\%-75\%; (4) >75\%; and (5) whole cross-section. A sixth class, "Not detected", is used for trees located on the stem map from field measurements and which does not have a cross-section in the LiDAR slice. In addition to the comparison of the quality of the stem point cloud between the scanning methods, we analyzed the influence of the stand characteristics and the terrain on the completeness of the point clouds. To test the significant effect of these environmental variables, we studied the relationship between the completeness of the cross-sections (proportion of closure) and the plots and terrain variables reported in the Table 1 . The significance of the factors was determined by using linear mixed-effects models with, as a random factor, the plot ID (function lme from the library nlme of the R software). As the dependent variable corresponds to a proportion of closure class, we fist converted it to a quantitative variable by replacing the class by the mid-class proportion value. Then, we applied an angular transformation (Equation (1)) in order to guarantee appropriate application conditions in the case of linear regressions [41]:

$$
Y^{\prime}=2 \arcsin \sqrt{Y}
$$

where $Y^{\prime}$ represents the transformed variable, and $Y$, the original one (i.e., the closure proportion of the cross section).

\subsection{Extraction of Forest Parameters from the Point Clouds}

The extraction of forest parameters was done with the open source software Computree using the algorithms from the ONF-ENSAM plugin [19]. The main steps used from this plugin are (1) terrain extraction and generation of rasters (a DTM and canopy height model: CHM) with a resolution which depends of the topography: $50 \mathrm{~cm}$ for flat plots and $10 \mathrm{~cm}$ for plots on slopes; (2) clustering of points; (3) creation of virtual logs; (4) skeletonization; and (5) stem mapping and DBH computation. The outputs of this process are a DTM, CHM, stem map, and DBH estimates. An interpolation and smoothing process was applied to the DTM to fill the pixels with missing values.

\subsection{Analysis}

Next, the comparison of the stem maps computed with Computree and the outcomes of the field inventory were compared in terms of the number of trees correctly detected (producer's accuracy) and falsely detected trees (commission error), as well as differences in tree location between scanning methods.

The DTM and CHM outputs were analyzed and the derived DBH values for the FARO1, FARO5, and ZEB1 datasets were compared to field measurements. The root mean square error (RMSE) and bias between the LiDAR DBH and the field DBH were calculated.

The significance of plot level factors (stand structure, understory, number of trees per hectare (NHA), and basal area per hectare (GHA)), the slope and tree level factors (species, DBH, and bark roughness class of the species) on the quality of DBH estimates (difference between LiDAR DBH and field $\mathrm{DBH}$ ) was tested by using a linear mixed-effects models with, as a random factor, the plot ID.

\section{Results}

\subsection{Data Collection}

The different scanning setups show large differences in the time which is needed to acquire and process the point cloud data. Positioning the spheres in the plot for registering the scans of the MS method is time consuming compared to the other measurements methods (40 min compared to 6 min for the FARO scanner and $11 \mathrm{~min}$ for ZEB1 (Table 2)). Setting up the plot and scanning from five locations with the TLS (FARO5) takes three times longer than scanning with ZEB1. The SS method and scanning with ZEB1 take less time than field measurements. 
Table 2. Acquisition and processing time for the different scanning setups (SS: FARO1, MS: FARO5, and HMLS: ZEB1).

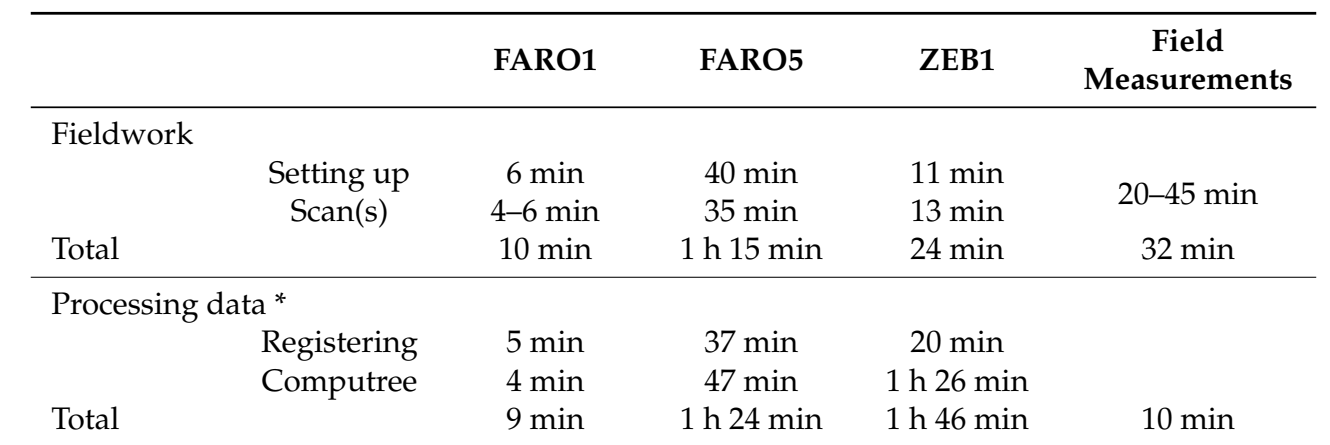

The setting up line in the table refers to the preparation of the scanner for FARO1, to the installation of the spheres and the preparation of the scanner for the FARO5 and to the preparation of the scanner and the initialization of the IMU for the ZEB1. Field measurements were measurement of the DBH with tape and determining the position of the trees (azimuth and distance). *the processing of the data is done by an experienced person. The registration time of the ZEB1 scans only includes the processing at the GeoSLAM server.

\subsection{TLS Pre-Processing}

The registration of the five scans (FARO5) was done with a minimum precision of $4 \mathrm{~mm}$ for the ten plots (i.e., the average difference of the spheres positions between the scans in the final point cloud is less than $4 \mathrm{~mm}$ ). The automatic co-registration of the ZEB1 scans gave satisfactory results for eight of the ten plots, although the exact precision cannot be determined. From the ZEB1 point cloud alone it could be determined that the automatic co-registration did not succeed for plot 2 and the quality of the registration of the plot 6 was not good enough for stem measurements. Plot 2 has a low number of trees, which hinders the object recognition in the SLAM algorithm, leading to a "slip" of the object recognition algorithm which results in a clearly different pattern than we walked. Plot 6 has a higher stem density, but also a dense understory with moving leaves. This understory might affect the co-registration of the ZEB1 scan too, which resulted in slight offsets of the points at the stems and presence of many double stems in the point cloud. Therefore, further analysis does not include plots 2 and 6.

\subsection{Visual Comparison}

Due to the limited range of the ZEB1, the laser does not reach most of the treetops and the point density in the upper canopy is rather low. A higher proportion of the points are located to the lower height level in the ZEB1 point clouds compare the TLS one. This higher proportion of points in the lower part of the plots with ZEB1 is due to the higher beam divergence of the ZEB1 and to the oscillating movement of the 2D scanner, which is in favor of horizontal scanning.

A comparison between the FARO5 and ZEB1 setup shows that the point clouds acquired with the ZEB1 is much noisier. Nevertheless, the points of the ZEB1 slice appear to be within and outside the stem and the density of points around the trunk follows a Gaussian shape with a mode located in the outline of the cross section (Figure 3). Indeed, the point density modes of the ZEB1 chart bar ( $5 \mathrm{~mm}$ in width) in transects of the transversal slice of the trunk match with the modes of FARO5 (red and yellow dashed lines). Fitting cylinders to the trunk should, therefore, result in the same diameters using the two technologies. 
ZEB1
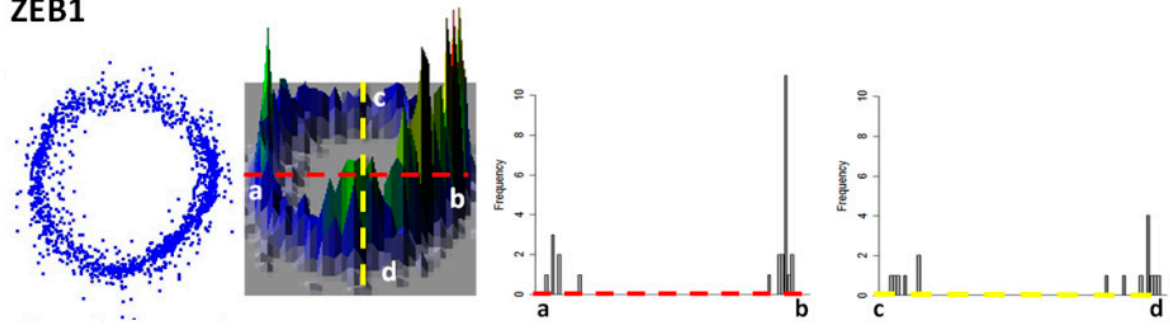

\section{FARO5}
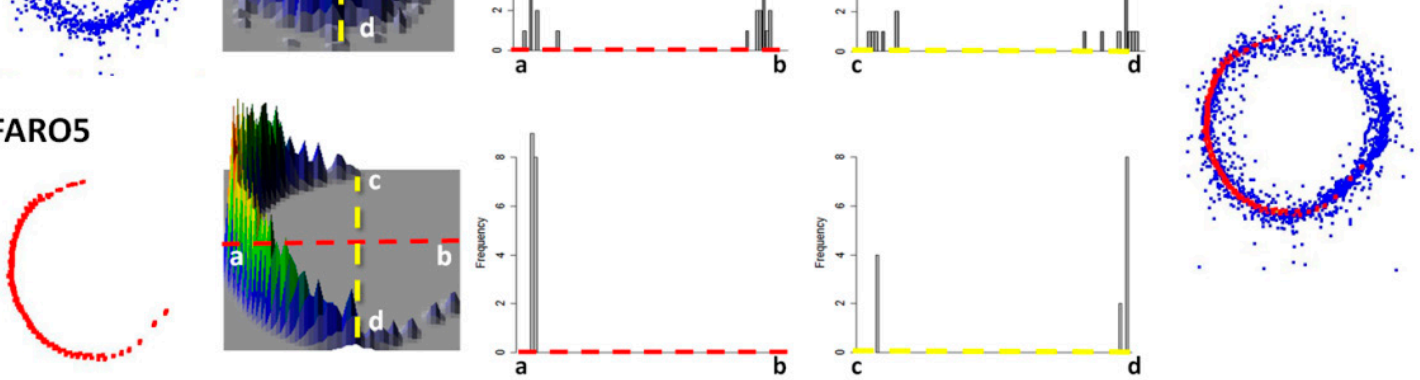

Figure 3. Comparison of a $1.3 \mathrm{~m}$ height slice of the point cloud (thickness of $10 \mathrm{~cm}$ ) of one Picea abies stem scanned with the hand-held mobile laser scanning ZEB1 and with the multiscan method (FARO5). From the left, we have the top view of the slices, the 3D density graph of the slices, histograms of transects within the slices with bins of $5 \mathrm{~mm}$ (red dotted line are transects following the $\mathrm{x}$ axis and the yellow dotted line are transects following the y axis) and, finally, on the right, we have an overlay of the ZEB1 slice and the FARO5 slice.

\subsection{The Success of Scanning Trees}

In the eight plots studied, the number of trees detected from the LiDAR scans compared to the field inventory data shows that all the trees $(\mathrm{DBH}>10 \mathrm{~cm})$ were detected with the FARO5 and ZEB1 scanning method, whereas $17 \%$ of the trees are not detected when using a single scan (FARO1) (Figure 4). Due to the high number of scan positions with the ZEB1, this method results in the best spatial cover throughout the plot. As a result, the percentage of trees for which more than half of the cross-section is scanned is $1 \%, 79 \%$, and $93 \%$ respectively for FARO1, FARO5, and ZEB1 setups (Figure 4). The whole cross-section is scanned for no trees with FARO1, for $42 \%$ of the trees with FARO5, and for $91 \%$ of the trees with ZEB1. The observations of the cross-section at $1.3 \mathrm{~m}$ height further showed that two trees were measured twice during the field survey in the dense plot 8 , indicating that errors may also occur in field inventories.

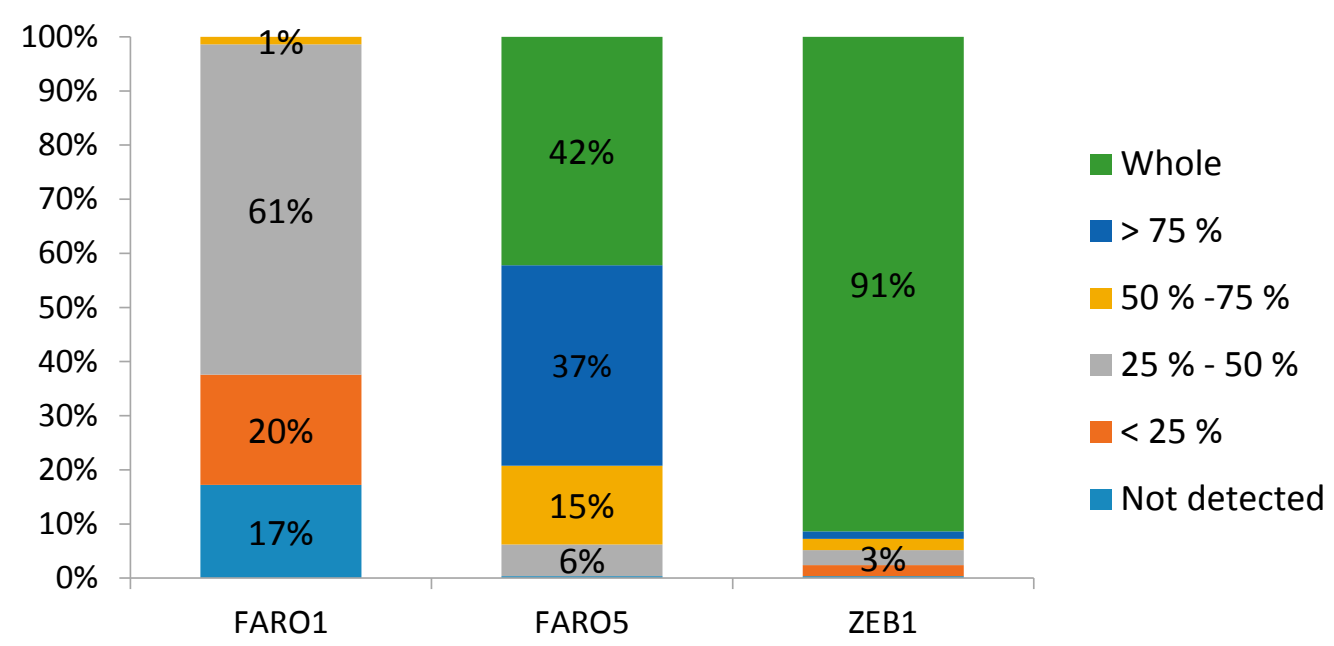

Figure 4. Percentage of the cross-section closure between the three different scanning methods according to the visual interpretation of the point cloud slices at $1.3 \mathrm{~m}$ height (thickness of $10 \mathrm{~cm}$ ) of the eight plots. 
The influence of stand factors and the slope for scanning trees are different for the scanning methods. The main significant factor affecting the proportion of the trees scanned for FARO1 is the slope. For FARO5, the only significant factor is the combination of NHA and GHA (NHA $\times$ GHA) whereas for ZEB1, the understory is the only significant factor (the coefficient of the random effect of the plots is limited and the $p$-values are, respectively, 0.00, 0.01, and 0.01 for FARO1, FARO5, and ZEB1 models).

\subsection{Extraction of Forest Parameters}

\subsubsection{DTM and CHM Comparison}

By subtracting the DTM rasters between the different scanning methods, no observable bias is noticed, but for plots on a slope (plots 1 and 4), there are local pixel differences when comparing the FARO1 DTM with the FARO5 DTM (Figure 5). These differences are mainly between $-1 \mathrm{~m}$ and $1 \mathrm{~m}$, with some deviations up to $-3.6 \mathrm{~m}$ and $3.5 \mathrm{~m}$ and outliers up to $12 \mathrm{~m}$ (plot 1 ) or $18 \mathrm{~m}$ (plot 4). The DTM differences between FARO1 and FARO5 have much larger variation for the sloping plots (plots 1-5), compared to the flat plots (plots 7-10) (Figure 5). As we do not have the same difference between the DTM of FARO5 and ZEB1, the local DTM divergence of FARO1 would mainly be the result of the scanning setup which engenders large occluded area. Refining parameters (e.g., reducing the resolution from $10 \mathrm{~cm}$ to $50 \mathrm{~cm}$ ) for the DTM generation may reduce these local differences. DTMs generated from FARO5 and ZEB1 are similar with only a slight bias (less than $20 \mathrm{~cm}$ ) for the DTM difference of plot 4 (Figure 5). The high herbaceous strata in plot 4 may explain this higher variation between FARO5 and ZEB1 DTMs.
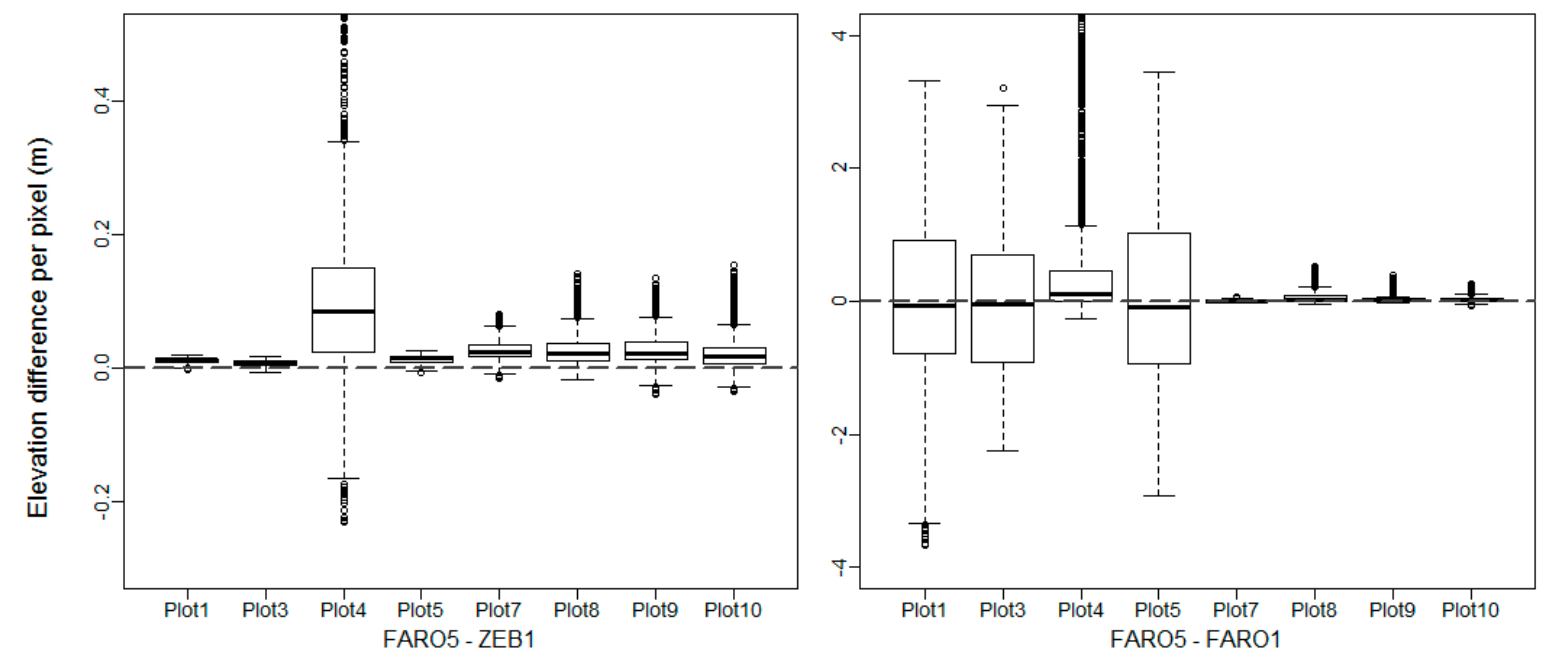

Figure 5. DTM differences comparing different scan setups. The bias is generally low, but slope and understory leads to variation in the generated DTMs (note that the $y$-axis scale is different for the two graphs).

The CHM differences between the setups are shown for each plot in Figure 6. The FARO1 setup is not suitable for studying the canopy top for plots of $15 \mathrm{~m}$ radius. Based on Figure 7, with FARO1 a reliable canopy height analysis might be done for a plot of maximum $5 \mathrm{~m}$ radius. For FARO1, the mean canopy height is on average underestimated by $3.1 \mathrm{~m}$ (Figure 6 and Table 3 ) and the CHM is highly variable compared to the other setups (high coefficient of variation: $\mathrm{CV}$ in Table 3). The CHM derived from ZEB1 data never reaches a height of $25 \mathrm{~m}$, which is the range limit of the ZEB1 LiDAR scanner (Table 3). Moreover, an important part of the lasers does not overpass 15 to $20 \mathrm{~m}$ (Table 3 and Figure $7 \mathrm{c}, \mathrm{d})$. This range limitation explains the important differences noticed for the plots $3,4,8$, and 9 (Figure 6 and Table 3). In plot 4, the stand is a mature even-aged stand of Douglas (Pseudotsuga 
menziesii) with crowns starting at a height of 20-25 m and total heights reaching 40-45 m, which explain the high CHM difference (up to $40 \mathrm{~m}$ ) noticed in the Figure 6.
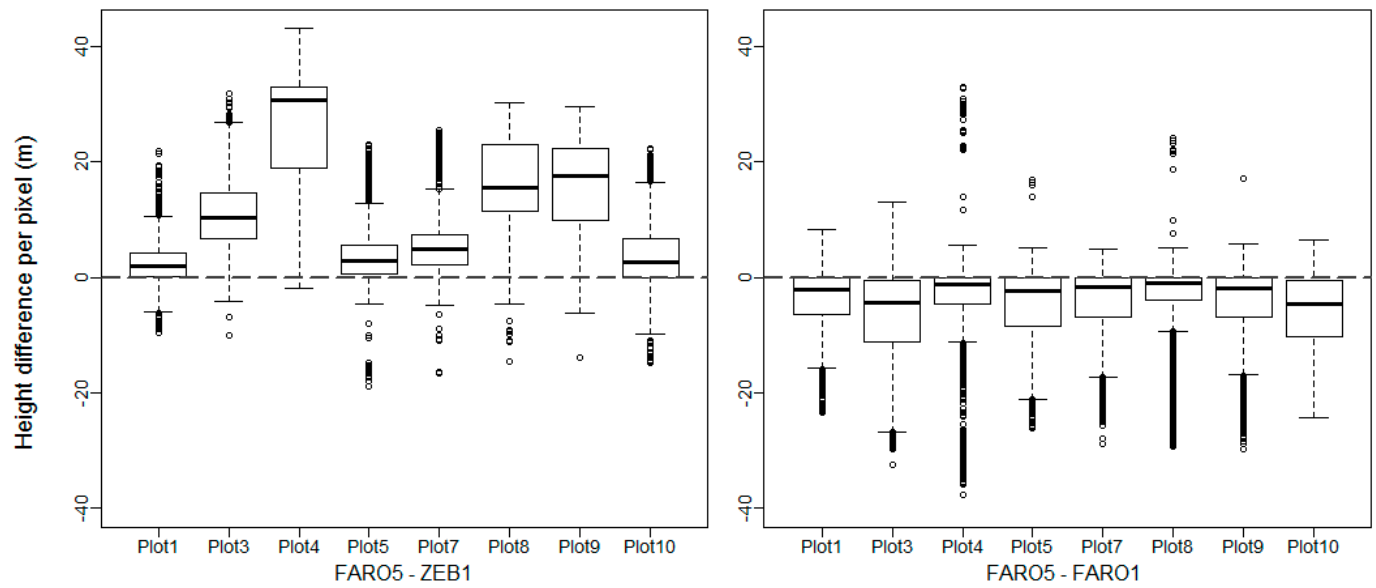

Figure 6. CHM differences comparing different scan setups.

Plot 3
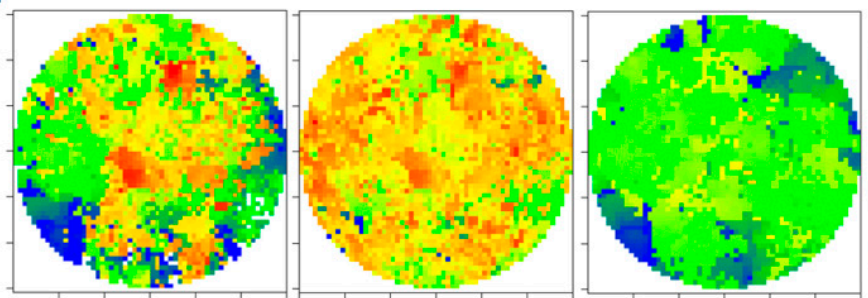

Plot 5

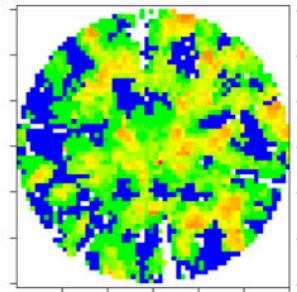

FARO1

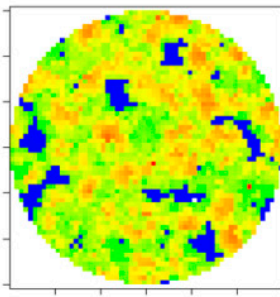

FARO5

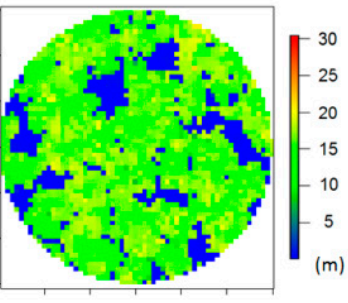

ZEB1

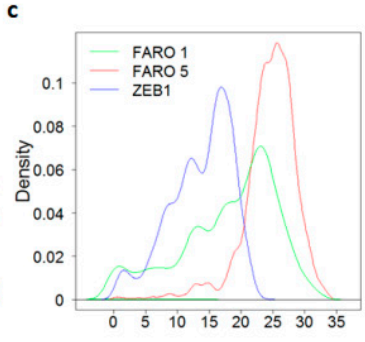

Height $(m)$

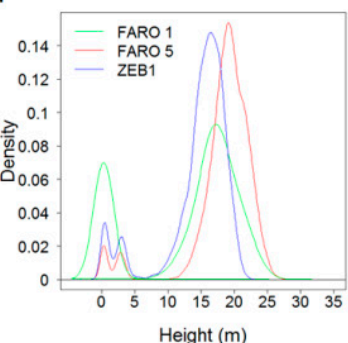

Figure 7. CHM illustration of two plots with the three different scanning methods.

Table 3. The maximum, mean, and coefficient of variation (standard deviation/mean) of the CHM heights of the different scanning setups.

\begin{tabular}{|c|c|c|c|c|c|c|c|c|c|}
\hline \multirow{2}{*}{ Plot } & \multicolumn{3}{|c|}{ FARO1 } & \multicolumn{3}{|c|}{ FARO5 } & \multicolumn{3}{|c|}{ ZEB1 } \\
\hline & $\operatorname{Max}(\mathrm{m})$ & Mean (m) & CV (\%) & $\operatorname{Max}(\mathrm{m})$ & Mean (m) & CV (\%) & $\operatorname{Max}(\mathrm{m})$ & Mean (m) & CV (\%) \\
\hline 1 & 22.6 & 14.1 & 34 & 29.5 & 17.4 & 17 & 22.1 & 14.9 & 17 \\
\hline 3 & 32.8 & 19.0 & 40 & 33.5 & 24.5 & 17 & 24.0 & 14.0 & 34 \\
\hline 4 & 40.4 & 29.9 & 38 & 45.9 & 33.0 & 39 & 24.6 & 15.8 & 29 \\
\hline 5 & 30.6 & 17.5 & 46 & 30.4 & 18.9 & 26 & 21.9 & 15.3 & 32 \\
\hline 7 & 26.1 & 17.5 & 43 & 29.0 & 20.1 & 21 & 21.3 & 15.2 & 29 \\
\hline 8 & 33.3 & 23.5 & 31 & 33.3 & 25.3 & 15 & 21.0 & 12.6 & 50 \\
\hline 9 & 32.0 & 21.0 & 43 & 30.7 & 22.9 & 23 & 22.3 & 12.7 & 52 \\
\hline 10 & 25.7 & 10.4 & 46 & 28.6 & 15.9 & 38 & 21.7 & 12.2 & 32 \\
\hline
\end{tabular}

Only pixels with a height of more than $2 \mathrm{~m}$ were used to compute the mean and the standard deviation. 


\subsubsection{Stem Mapping and DBH Estimation}

Processing the point clouds of FARO1, FARO5 and ZEB1 with Computree results in an average true tree detection rate (producer's accuracy for trees with DBH $>10 \mathrm{~cm}$ ) of, respectively, $78 \% \pm 18 \%$, $93 \% \pm 8 \%$, and $90 \% \pm 12 \%$, and an average percentage of false trees (commission error) of $21 \% \pm 18 \%$, $22 \% \pm 21 \%$, and $31 \% \pm 24 \%$. The average difference between stem locations of FARO5-FARO1, FARO5-ZEB1 is, respectively, $2.8 \pm 14 \mathrm{~cm}$ and $4.2 \pm 7.5 \mathrm{~cm}$. So, deformations, from drift or bad registration of the ZEB1 point clouds, are not observed in the eight plots.

In comparison to field DBH measurements, the FARO5 and ZEB1 setups show similar reliable DBH estimates, with a bias lower than $-0.2 \mathrm{~cm}$ and a RMSE lower than $1.5 \mathrm{~cm}$ (Figure 8, Table 4). DBH of almost all correctly-detected trees is determined with an accuracy of $<3 \mathrm{~cm}$ (respectively $96 \%$ and $98 \%$ of the trees scanned for FARO5 and ZEB1). These rates decrease to, respectively, $78 \%$ and $73 \%$ for an accuracy $<1 \mathrm{~cm}$. The bias and the RMSE of FARO1 is much higher compared to the two other setups with a relative RMSE of $13.4 \%$, while it is less than $5 \%$ for the others setups. The FARO1 setup results in a clearly worse performance of the DBH determination showing that the circle-fitting used in our method is not able to deal with incomplete scanning of tree stems, where the algorithm has no problem estimating DBH with the "noisy" data from ZEB1.

Table 4. Summary statistics of DBH fitting of all the trees detected by each setup. The root mean square error (RMSE) in percentage is the RMSE divided by the mean DBH.

\begin{tabular}{cccc}
\hline Setup & Bias & RMSE (cm) & RMSE (\%) \\
\hline FARO1 & -1.17 & 3.73 & 13.4 \\
FARO5 & -0.17 & 1.3 & 4.7 \\
ZEB1 & -0.08 & 1.11 & 4.1 \\
\hline
\end{tabular}

Depending of the scanning method, one or two factors at the tree level have a significant effect on DBH estimates: the bark-roughness of the species (smooth or rough) and the size of the tree (DBH). For FARO1, only the bark-roughness has a highly significant effect on the accuracy of DBH estimates, with a higher negative bias for species with rough bark $(p=0.00016)$. For FARO5, the size of the tree and the bark roughness with the mean slope of the plot have a significant effect on the accuracy of DBH estimates $(p=0.0001)$. Finally, with ZEB1, both tree level factors have a significant effect on the accuracy of DBH estimates $\left(p=2.2 \times 10^{-16}\right)$, but the random factor plot is also significant $\left(p=2.7 \times 10^{-5}\right)$. The significance of the factor plot may hide the influence of another variable as the registration quality with the SLAM algorithm. Nevertheless, the Figure 8 shows the high relationship between DBH accuracy and size of the trees for ZEB1. 

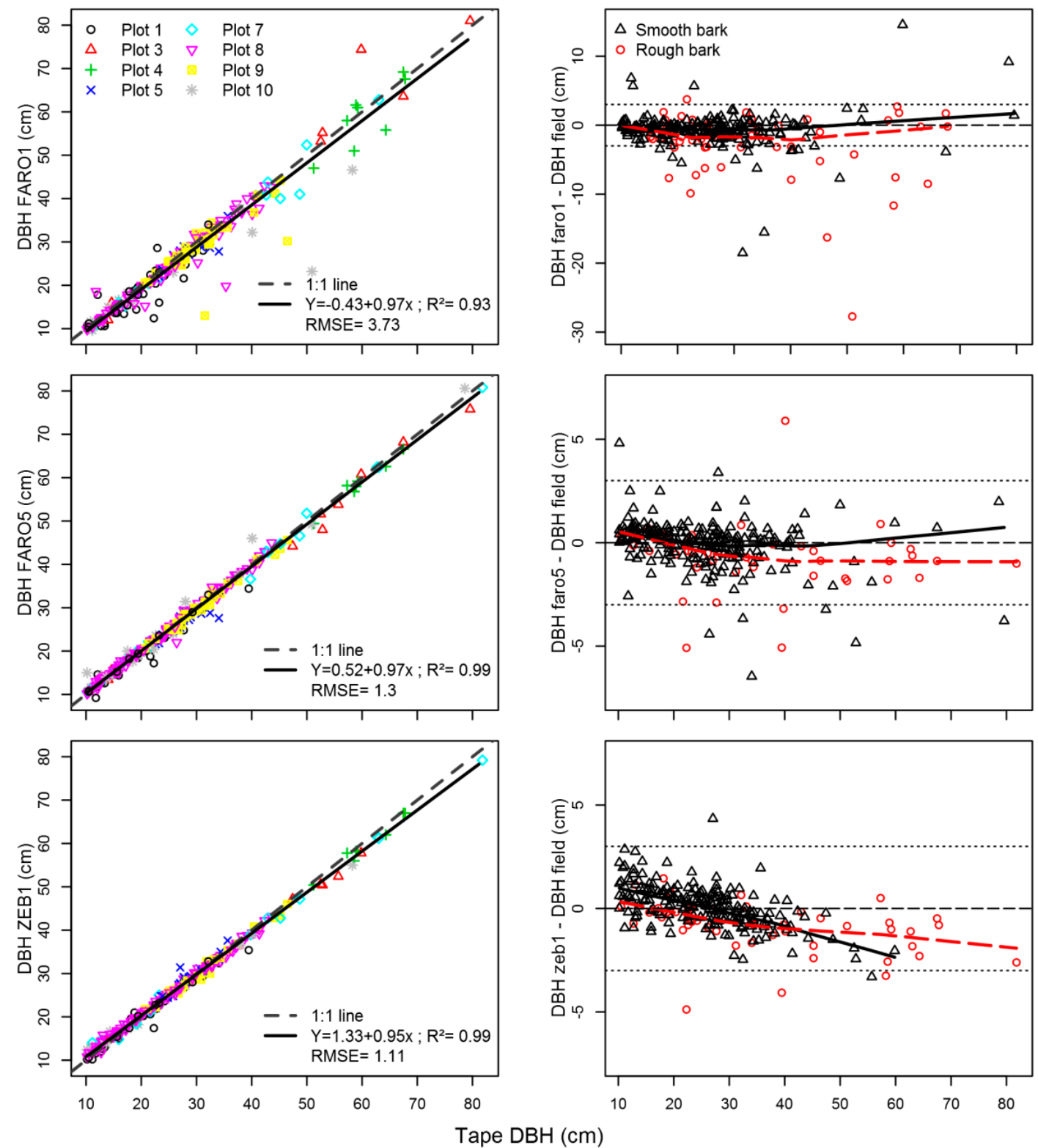

Figure 8. On the left, scatterplots of the DBH measured with the tape versus the DBH derived from the different LiDAR data of all the trees detected. The dashed line shows the 1:1 line and the solid line the trend-line. On the right, the diameter difference between DBH estimates from LiDAR and DBH measured in the field with a tape (the $y$ scale of the residual plot of FARO 1 is different to the other residual plots). The solid grey curve is composed of local fitted lines (LOESS fitting with a span of $2 / 3$ ) for the species classified as smooth bark species and the long dashed red curve shows local fitted lines for the rough bark species. The $y$ values of the horizontal dotted lines are, respectively, $3 \mathrm{~cm}$ and $-3 \mathrm{~cm}$, which are threshold values discussed in the results.

\section{Discussion}

The SS method has on average a tree detection rate of $80 \%$ in all boreal and temperate forest types (Table S1). With SS, scanning trees at $1.3 \mathrm{~m}$ height in sloping terrain is more difficult as branches above $1.3 \mathrm{~m}$ height of the surrounding trees occlude the stems of the trees of the lower part of the plot and low vegetation (under $1.3 \mathrm{~m}$ height) occlude the stems of the upper part of the plot. The MS method increases the tree detection rate to more than $95 \%$ for plots with an area of less than 0.15 ha. The use of a HMLS allows a better tree detection rate than MS TLS and with a very competitive acquisition time. 
The HMLS combined with SLAM algorithms have a better registration accuracy in forest environments compared to the traditional MLS registering process, which uses GNSS data. Nevertheless, the high beam divergence of the HMLS reduces the penetration of the laser through the understory compared to the scanner used in TLS.

For plots with an area of less than 0.10 ha, SS and MS TLS methods, as well as HMLS using SLAM algorithms, produce suitable DTMs. The SS approach can then be used for DTM production in traditional forest inventory plots in order to combine it with ALS data. The ability of TLS to directly measure the height of the canopy top is limited because of occlusion. Due to the limited range and the high beam divergence of the HMLS it is also not possible to get reliable information of the canopy top. HMLS with a higher range and a lower beam divergence still needs to be tested for canopy top description. Otherwise, the combination of TLS data with aerial information as ALS or photogrammetric point cloud will offer a unique complete 3D description of the forest structure.

Comparing SS and MS DBH estimates with the same scanner show that partial information of the cross section of the trees limits the accuracy and the precision of the DBH estimates (Table S1). Moreover, the roughness of the bark seems to have influence in the accuracy of TLS DBH estimates based on circle fitting, as Brolly and Kiraly [42] noticed. The low precision of the HMLS scanner and the use of the SLAM algorithm for the registration do not impact the global accuracy and precision of DBH estimates. Nevertheless, with the HMLS, the DBH accuracy may be significantly influenced by the quality of the SLAM registration in the plot and the size of the tree. The influence of this last factor is also noticed by Ryding et al. [35]. The roughness of the bark also seems to have an influence. The high completeness of the cross-section scanned with HMLS could also reintroduce other methods for estimating the basal area of the cross-section, such a polygons [43], free-form curves [44], or mesh adjustment.

The high influence of the size of the tree for DBH estimates of completely-scanned trunks (which is the case for trees scanned with MS TLS and HMLS) might be explained by two factors. First, the larger the tree, the more irregular the shape of the base of the trunk is and the rougher the bark is. The irregularities at the base of the trunk might induce an overestimation of the diameter measured with the tape as the tape measures the convex hull of the cross-section. On the other hand, least square circle fitting on irregular cross-sections, as well as on a tree with rough bark, will induce lower diameter estimation than tape measurement as the concave parts of the irregular cross section and of the bark weight in the circle fitting. Secondly, the smaller the tree, the higher the chances that the tree will have low branches and having other small trees with low branches surrounding it. These low branches will have an influence in the least square circle fitting by inducing an overestimation of the diameter. Due to its high beam divergence, the HMLS is more sensitive to these small branches than the MS TLS approach.

The algorithms used to extract DBH still need improvements at two levels: the estimation of the breast height $(1.3 \mathrm{~m})$ and filtering the false trees detected. The challenging issues of these two points are not often discussed in the forestry TLS literature, whereas some other studies also show a high proportion of false trees (11\% in [14], 12\% in [45], $0 \%-1.4 \%$ in [42], $1 \%-2 \%$ in [46], 6\% in [47], and $14.4 \%$ in [28]). Results which are influenced by the DBH threshold chosen in their studies. In forestry, the ground level (height $=0 \mathrm{~m}$ ) is defined as the highest point of the ground around the tree. The algorithms used to extract the DBH do not always use this definition. The comparison with field measurement could then be more difficult if the breast height is not marked on the trunk for comparing the point of measurement prior to the analysis of the DBH estimates. In this study we adjusted the theoretical height of the algorithm to be, on average, in accordance with the point measurement used in the field.

The use of PLS, such as HMLS, for scanning the forest is promising for the description of the 3D structure of the forest. These scanners will be able to scan larger areas than TLS. The registering success is still a challenging issue when the SLAM algorithm is used with the HMLS data as $20 \%$ of the plots were not registered properly and $\mathrm{DBH}$ estimates of the remaining plots were also influenced by the 
quality of the registration (significance of the random effect of the plots). In addition to improvements in the registering process, a scanner with a higher range and a lower beam divergence will increase the quality of scanning forest with HMLS. With the current equipment it is not possible to scan the top of canopy and determine tree height, which would be important to estimate, e.g., timber volume and biomass accurately.

\section{Conclusions}

The use of a human operator as a mobile platform for laser scanning will significantly reduce the actual limitation for acquisition of 3D laser data in forests. The recent progress in automatic registration of scans and the reduction of the weight of the scanners has taken laser scanning to an operational level to retrieve the 3D structure of the forest and for forest monitoring. When acquisition speed is most important, Single Scan TLS is fastest, but the analysis of these data shows that a large number of trees remains undetected and the partial scanning of the trees results in low usability. HMLS is faster than Multi Scan TLS and yields better results for a number of tree parameters (DBH and tree detection). However, due to the limited range of the ZEB1 used in this study, the canopy is poorly described, resulting in a low usability of HMLS for heights above 15-20 m. With HMLS, almost the entire section at breast height of all of the trees is scanned, which will reintroduce other methods than circle or cylinder fitting to estimate basal area and volumes at the stand level. The actual challenging issue are processing scanner data at the plot or stand level. Automatic tree detection still needs to be improved and the volume estimates of the trees processed at the stand level need to be validated. Relating these data to other remote sensing data will offer new, accurate field data to upscale forest parameters, such as basal area or stand volume.

Supplementary Materials: The following are available online at http:/ /www.mdpi.com/1999-4907/7/6/127, Figure S1: Images of the 10 forest plots studied, Table S1: Summary of experimental design, scanner settings, and methodologies of previous studies on automatic stem detection and DBH extraction from TLS data for forest inventory.

Acknowledgments: We thank Fond Français pour l'Environement through the DynAfFor project and the World Bank through the PreREDD+ project who financially supported the time spent by S.B. for this research. We also thank the technical team of the Forest Resources Management unit of Gembloux Agro Bio Tech (University of Liège) who assisted us for field work and Nature + for their administrative support.

Author Contributions: S.B., H.B. and K.C. designed the study, S.B. and H.B. conducted the fieldwork; S.B. did most of the data-analysis; H.B., S.B. and K.C. wrote the manuscript and P.L. supervised the research and reviewed the manuscript.

Conflicts of Interest: The authors declare no conflict of interest. The founding sponsors had no role in the design of the study; in the collection, analyses, or interpretation of data and in the writing of the manuscript.

\section{References}

1. Newnham, G.J.; Armston, J.D.; Calders, K.; Disney, M.I.; Lovell, J.L.; Schaaf, C.B.; Strahler, A.H.; Danson, F.M. Terrestrial laser scanning for plot-scale forest measurement. Curr. For. Rep. 2015, 1, 239-251. [CrossRef]

2. Liang, X. Feasibility of Terrestrial Laser Scanning for Plotwise Forest Inventories. Available online: http: / /lib.tkk.fi/Diss/2013/isbn9789517112994/isbn9789517112994.pdf (accessed on 15 June 2016).

3. Lovell, J.L.; Jupp, D.L.B.; Newnham, G.J.; Culvenor, D.S. Measuring tree stem diameters using intensity profiles from ground-based scanning lidar from a fixed viewpoint. ISPRS J. Photogramm. Remote Sens. 2011, 66, 46-55. [CrossRef]

4. Van Leeuwen, M.; Nieuwenhuis, M. Retrieval of forest structural parameters using LiDAR remote sensing. Eur. J. For. Res. 2010, 129, 749-770. [CrossRef]

5. Erikson, M.; Karin, V. Finding tree-stems in laser range images of young mixed stands to perform selective cleaning. In Proceedings of the ScandLaser Scientific Workshop on Airborne Laser Scanning of Forest, Umea, Sweden, 3-4 September 2003. 
6. Simonse, M.; Aschoff, T.; Spiecker, H.; Thies, M. Automatic determination of forest inventory parameters using terrestrial laserscanning. In Proceedings of the ScandLaser Scientific Workshop on Airborne Laser Scanning of Forest, Umea, Sweden, 3-4 September 2003; Volume 2003, pp. 252-258.

7. Watt, P.J.; Donoghue, D.N.M.; Dunford, R.W. Forest Parameter Extraction Using Terrestrial Laser Scanning. Available online: http://www.natscan.uni-freiburg.de/suite/pdf/030916_1642_1.pdf (accessed on 15 June 2016).

8. Aschoff, T.; Thies, M.; Spiecker, H. Describing forest stands using terrestrial laser-scanning. Int. Arch. Photogramm. Remote Sens. Spat. Inf. Sci. 2004, 35, 237-241.

9. Haala, N.; Reulke, R.; Thies, M.; Aschoff, T. Combination of Terrestrial Laser Scanning with High Resolution Panoramic Images for Investigations in Forest Applications and Tree Species Recognition. Available online: http://www.isprs.org/proceedings/XXXIV/5-W16/papers/PanoWS_Dresden2004_Haala.pdf (accessed on 15 June 2016).

10. Hopkinson, C.; Chasmer, L.; Young-Pow, C.; Treitz, P. Assessing forest metrics with a ground-based scanning lidar. Can. J. For. Res. 2004, 34, 573-583. [CrossRef]

11. Thies, M.; Spiecker, H. Evaluation and future prospects of terrestrial laser scanning for standardized forest inventories. Forest 2004, 2,1.

12. Côté, J.-F.; Widlowski, J.-L.; Fournier, R.A.; Verstraete, M.M. The structural and radiative consistency of three-dimensional tree reconstructions from terrestrial lidar. Remote Sens. Environ. 2009, 113, 1067-1081. [CrossRef]

13. Fleck, S.; Mölder, I.; Jacob, M.; Gebauer, T.; Jungkunst, H.F.; Leuschner, C. Comparison of conventional eight-point crown projections with LIDAR-based virtual crown projections in a temperate old-growth forest. Ann. For. Sci. 2011, 68, 1173-1185. [CrossRef]

14. Bienert, A.; Scheller, S.; Keane, E.; Mohan, F.; Nugent, C. Tree Detection and Diameter Estimations by Analysis of Forest Terrestrial Laserscanner Point Clouds. Available online: http://www.isprs.org/proceedings/ XXXVI/3-W52/final_papers/Bienert_2007.pdf (accessed on 15 June 2016).

15. Calders, K.; Newnham, G.; Burt, A.; Murphy, S.; Raumonen, P.; Herold, M.; Culvenor, D.; Avitabile, V.; Disney, M.; Armston, J.; et al. Nondestructive estimates of above-ground biomass using terrestrial laser scanning. Methods Ecol. Evol. 2015, 6, 198-208. [CrossRef]

16. Côté, J.-F.; Fournier, R.A.; Egli, R. An architectural model of trees to estimate forest structural attributes using terrestrial LiDAR. Environ. Model. Softw. 2011, 26, 761-777. [CrossRef]

17. Dassot, M.; Colin, A.; Santenoise, P.; Fournier, M.; Constant, T. Terrestrial laser scanning for measuring the solid wood volume, including branches, of adult standing trees in the forest environment. Comput. Electron. Agric. 2012, 89, 86-93. [CrossRef]

18. Lefsky, M.; McHale, M.R. Volume estimates of trees with complex architecture from terrestrial laser scanning. J. Appl. Remote Sens. 2008, 2, 023521.

19. Othmani, A.; Piboule, A.; Krebs, M.; Stolz, C.; Voon, L.L.Y. Towards Automated and Operational Forest Inventories with T-Lidar. Available online: https://hal.archives-ouvertes.fr/hal-00646403/document (accessed on 15 June 2016).

20. Raumonen, P.; Casella, E.; Calders, K.; Murphy, S.; AAkerblom, M.; Kaasalainen, M. Massive-scale tree modelling from TLS data. ISPRS Ann. Photogramm. Remote Sens. Spat. Inf. Sci. 2015, 2, 189-196. [CrossRef]

21. Huang, H.; Li, Z.; Gong, P.; Cheng, X.; Clinton, N.; Cao, C.; Ni, W.; Wang, L. Automated methods for measuring DBH and tree heights with a commercial scanning lidar. Photogramm. Eng. Remote Sens. 2011, 77, 219-227. [CrossRef]

22. García, M.; Danson, F.M.; Riano, D.; Chuvieco, E.; Ramirez, F.A.; Bandugula, V. Terrestrial laser scanning to estimate plot-level forest canopy fuel properties. Int. J. Appl. Earth Obs. Geoinform. 2011, 13, 636-645. [CrossRef]

23. Strahler, A.H.; Jupp, D.L.; Woodcock, C.E.; Schaaf, C.B.; Yao, T.; Zhao, F.; Yang, X.; Lovell, J.; Culvenor, D.; Newnham, G.; et al. Retrieval of forest structural parameters using a ground-based lidar instrument (Echidna ${ }^{\circledR}$ ). Can. J. Remote Sens. 2008, 34, S426-S440. [CrossRef]

24. Danson, F.M.; Hetherington, D.; Morsdorf, F.; Koetz, B.; Allgöwer, B. Forest canopy gap fraction from terrestrial laser scanning. IEEE Geosci. Remote Sens. Lett. 2007, 4, 157-160. [CrossRef]

25. Lovell, J.L.; Haverd, V.; Jupp, D.L.B.; Newnham, G.J. The Canopy Semi-analytic P gap and Radiative Transfer (CanSPART) model: Validation using ground based LiDAR. Agric. For. Meteorol. 2012, 158, 1-12. [CrossRef] 
26. Hosoi, F.; Omasa, K. Factors contributing to accuracy in the estimation of the woody canopy leaf area density profile using 3D portable lidar imaging. J. Exp. Bot. 2007, 58, 3463-3473. [CrossRef] [PubMed]

27. Jupp, D.L.; Culvenor, D.S.; Lovell, J.L.; Newnham, G.J. Evaluation and validation of canopy laser radar (LIDAR) systems for native and plantation forest inventory. Final Report to the Forest and Wood Products Research E Development Corporation (FWPRDC: PN 02.2902) CSIRO 2005, 20, 192-197.

28. Liang, X.; Kukko, A.; Kaartinen, H.; Hyyppä, J.; Yu, X.; Jaakkola, A.; Wang, Y. Possibilities of a Personal Laser Scanning System for Forest Mapping and Ecosystem Services. Sensors 2014, 14, 1228-1248. [CrossRef] [PubMed]

29. Kaartinen, H.; Hyyppä, J.; Kukko, A.; Jaakkola, A.; Hyyppä, H. Benchmarking the performance of mobile laser scanning systems using a permanent test field. Sensors 2012, 12, 12814-12835. [CrossRef]

30. Jaakkola, A.; Hyyppä, J.; Kukko, A.; Yu, X.; Kaartinen, H.; Lehtomäki, M.; Lin, Y. A low-cost multi-sensoral mobile mapping system and its feasibility for tree measurements. ISPRS J. Photogramm. Remote Sens. 2010, 65, 514-522. [CrossRef]

31. Rutzinger, M.; Pratihast, A.K.; Oude Elberink, S.; Vosselman, G. Detection and modelling of 3D trees from mobile laser scanning data. Int. Arch. Photogramm. Remote Sens. Spat. Inf. Sci. 2010, 38, 520-525.

32. Holopainen, M.; Kankare, V.; Vastaranta, M.; Liang, X.; Lin, Y.; Vaaja, M.; Yu, X.; Hyyppä, J.; Hyyppä, H.; Kaartinen, H.; et al. Tree mapping using airborne, terrestrial and mobile laser scanning-A case study in a heterogeneous urban forest. Urban For. Urban Green. 2013, 12, 546-553. [CrossRef]

33. Kukko, A.; Kaartinen, H.; Hyyppä, J.; Chen, Y. Multiplatform mobile laser scanning: Usability and performance. Sensors 2012, 12, 11712-11733. [CrossRef]

34. Bosse, M.; Zlot, R.; Flick, P. Zebedee: Design of a spring-mounted 3-d range sensor with application to mobile mapping. IEEE Trans. Robot. 2012, 28, 1104-1119. [CrossRef]

35. Ryding, J.; Williams, E.; Smith, M.J.; Eichhorn, M.P. Assessing Handheld Mobile Laser Scanners for Forest Surveys. Remote Sens. 2015, 7, 1095-1111. [CrossRef]

36. James, M.R.; Quinton, J.N. Ultra-rapid topographic surveying for complex environments: The hand-held mobile laser scanner (HMLS). Earth Surf. Process. Landf. 2014, 39, 138-142. [CrossRef]

37. Trochta, J.; Král, K.; Janík, D.; Adam, D. Arrangement of terrestrial laser scanner positions for area-wide stem mapping of natural forests. Can. J. For. Res. 2013, 43, 355-363. [CrossRef]

38. FARO Scene-version 5.4. FARO Verwaltungs GmbH. 2015. Available online: http://www.faro.com/ (accessed on 15 June 2016).

39. CloudCompare—version 2.6. Available online: http:/ /www.cloudcompare.org/ (accessed on 15 June 2016).

40. RIEGL LMS, RiSCAN PRO Version 2.0. Software Description and User's Instructions. 2016. Available online: http:/ / www.riegl.com/ (accessed on 15 June 2016).

41. Dagnélie, P. Statistique Théorique et Appliquée, Tome 2: Inférences à une et à Deux Dimensions; Bruxelles-Université, Ed.; De Boeck \& Larcier: Bruxelles, Belgium, 2006.

42. Brolly, G.; Kiraly, G. Algorithms for stem mapping by means of terrestrial laser scanning. Acta Silv. Lignaria Hung. 2009, 5, 119-130.

43. Wezyk, P.; Koziol, K.; Glista, M.; Pierzchalski, M. Terrestrial Laser Scanning versus Traditional Forest Inventory. First Results from the Polish Forests. Available online: http:/ /www.isprs.org/proceedings / XXXVI/3-W52/final_papers/Wezyk_2007.pdf (accessed on 15 June 2016).

44. Pfeifer, N.; Winterhalder, D. Modelling of tree cross sections from terrestrial laser scanning data with free-form curves. Int. Arch. Photogramm. Remote Sens. Spat. Inf. Sci. 2004, 36, 76-81.

45. Murphy, G. Determining stand value and log product yields using terrestrial lidar and optimal bucking: A case study. J. For. 2008, 106, 317-324.

46. Pueschel, P.; Newnham, G.; Rock, G.; Udelhoven, T.; Werner, W.; Hill, J. The influence of scan mode and circle fitting on tree stem detection, stem diameter and volume extraction from terrestrial laser scans. ISPRS J. Photogramm. Remote Sens. 2013, 77, 44-56. [CrossRef]

47. Schilling, A.; Maas, H.-G.; Lingnau, C. Tree detection by row recovery on Eucalyptus spp. Plantations from TLS data. In Proceedings of the EARSeL 34th Symposium, Warsaw, Poland, 16-20 June 2014.

(C) 2016 by the authors; licensee MDPI, Basel, Switzerland. This article is an open access article distributed under the terms and conditions of the Creative Commons Attribution (CC-BY) license (http://creativecommons.org/licenses/by/4.0/). 